\title{
Projeto Escola Cidade: o trabalho de enquadramento da memória nas práticas de militarização da infância (1931 -
} 1933)

\begin{abstract}
Resumo
Este estudo tem como foco a história do Instituto Ferreira Vianna no período de 1931 a 1933, quando foi implantado o projeto Escola Cidade na instituição. Há dois documentos que servem de fonte para a análise: um relatório do diretor da instituição à época, José Piragibe, para a Diretoria de Instrução Pública, e um livro de registro de ocorrências das inspetoras de disciplina, que revela os constrangimentos e rejeições pelos quais passaram os alunos dos diversos departamentos criados pelo projeto. As reflexões aqui levantadas permitem pensar sobre a elaboração do projeto civilizador republicano no interior da escola, que se refletiu nas práticas escolares voltadas para a militarização da infância, e nas experiências não reveladas pelos relatórios oficiais, buscando compreender como os sujeitos agem e pensam dentro de determinadas condições.
\end{abstract}

Palavras-chave: Instituto Ferreira Vianna; Projeto Escola-Cidade; Era Vargas.

\author{
Mariza da Gama Leite de Oliveira \\ Doutora em Educação pela \\ Universidade Federal do Rio de \\ Janeiro - UFRJ - Brasil \\ marizagoliva@gmail.com
}

\section{Para citar este artigo:}

OLIVEIRA, Mariza da Gama Leite de. Projeto Escola Cidade: o trabalho de enquadramento da memória nas práticas de militarização da infância (1931 - 1933). Revista Linhas. Florianópolis, v. 16, n. 31, p. 246 - 275 , maio/ago. 2015. 


\title{
The City School Project: the embodiment of memory in the practices of militarization of childhood (1931-1933)
}

\begin{abstract}
This study focuses on the history of the Ferreira Vianna Institute in the period 1931-1933, when it was deployed School-City Project at the institution. Two documents are used in the analysis: a report from the director of the institution at the time, José Piragibe to the Directorate of Public Instruction, and occurrences record book of discipline provincials, revealing the constraints and rejections they passed by students of various departments created by the project. The considerations raised here allow us to thin about the development of the republican civilizing project within the school, which reflected in facing the militarization of childhood school practices, and experiences not shown by the official reports, trying to understand how subjects act and think within certain conditions.
\end{abstract}

Keywords: Ferreira Vianna Institute; School-City Project; The Vargas Era. 
O Instituto Ferreira Vianna, hoje Escola Técnica Estadual Ferreira Vianna, da Fundação de Apoio à Escola Técnica (FAETEC/RJ), tem origem como instituição no final do século XIX, sob a denominação de Casa de São José (1888), com direção das irmãs de caridade, quando a cidade era Corte Imperial. Sua finalidade era abrigar crianças abandonadas na idade de 6 a 12 anos, do sexo masculino, órfãs e com risco de tornaremse desviantes na sociedade. De Corte Imperial a Distrito Federal, a cidade do Rio de Janeiro, capital e espaço de concretização do projeto modernizador da República, foi palco privilegiado da atuação do poder público no sentido de garantir a ordem e promover o progresso do país, ora por meio da repressão às classes populares, ora pela prestação de assistência àqueles considerados merecedores de auxílio.

A assistência à infância sofreu gradativa institucionalização na transição do século XIX para o XX, deixando de ser caritativa, e tornando-se cada vez mais científica, sob os olhares e cuidados de médicos e juristas, até tornar-se responsabilidade do Estado (RIZZINI, 1993; 2011). Nesse processo, desde sua origem, a instituição esteve ligada ao Ministério do Interior, à Secretaria Geral de Higiene e Assistência Pública e finalmente à Diretoria Geral de Instrução Pública, sendo incluída entre os estabelecimentos de ensino profissional na Era Vargas.

O recorte temporal do estudo compreende a década de 1930, por entender que este período foi um divisor de águas para as políticas educacionais do país, quando se reforçaram os projetos varguistas para alcance da fidelidade patriótica da criança e da juventude, adotando como estratégia práticas escolares voltadas para a valorização do trabalho e a militarização desse público.

Assim, através do relatório do diretor da instituição José Piragibe para a Diretoria de Instrução Pública e de registros contidos no livro das inspetoras de disciplina do período de 1931 a 1933, pretende-se reconstruir as relações que se estabeleceram entre os sujeitos que vivenciaram a experiência do Projeto Escola Cidade no Instituto Ferreira Vianna.

O artigo está dividido em quatro seções. Inicialmente será discutido o conceito de “Memória”, na perspectiva de Halbwachs (2003), Pierre Nora (1993), e Michael Pollak 
(1989), com o auxílio dos estudos de Pinto e Farias (2012). Estes últimos buscam construir o conceito de Memória Social, indicando o campo problemático de onde ele emerge, em decorrência de inserir-se num campo de lutas e de relações de poder, num constante embate entre lembrança e esquecimento. A este conceito será relacionado o de Nacionalismo e o de Cultura Escolar. Na segunda seção, conheceremos um dos projetos desenvolvidos no Instituto Ferreira Vianna - o Projeto Escola Cidade, que buscou desenvolver a autonomia, a cooperação e o trabalho entre os internos, regido por princípios de hierarquia militar entre os alunos. Na terceira parte, verificaremos através de registros não oficiais, os conflitos abertos gerados pelo projeto no cotidiano do internato, entre os "chefes", os alunos e as inspetoras de disciplina. Por fim, além da análise desta experiência, destacar-se-á a importância da preservação dos arquivos e acervos escolares, que podem fornecer material precioso para a reconstrução das práticas escolares.

\section{O “trabalho de enquadramento da memória": nacionalismo e cultura escolar}

A memória é vida, sempre carregada por grupos vivos e, nesse sentido, ela está em permanente evolução, aberta à dialética da lembrança e do esquecimento, inconsciente de suas deformações sucessivas, vulnerável a todos os usos e manipulações, susceptível de longas latências e de repentinas revitalizações. A história é a reconstrução sempre problemática e incompleta do que não existe mais. A memória é um fenômeno sempre atual, um elo vivido no eterno presente; a história, uma representação do passado. Porque é afetiva e mágica, a memória não se acomoda a detalhes que a confortam; ela se alimenta de lembranças vagas, telescópicas, globais ou flutuantes, particulares ou simbólicas, sensível a todas as transferências, cenas, censura ou projeções. A história, porque operação intelectual e laicizante, demanda análise e discurso crítico. A memória instala a lembrança no sagrado, a história a liberta, e a torna sempre prosaica. A memória emerge de um grupo que ela une, o que quer dizer, como Halbwachs o fez, que há tantas memórias quantos grupos existem, que ela é, por natureza, múltipla e desacelerada, coletiva, plural e individualizada. A história, ao contrário, pertence a todos e a ninguém, o que lhe dá uma vocação para o universal. A memória se enraíza no concreto, no espaço, no gesto, na imagem, no objeto. A história só se liga a continuidades temporais, às evoluções e às relações das coisas. A memória é um absoluto e a história só conhece o relativo. (NORA, 1993, p. 9) 
Com Nora (1993), entende-se o poder da memória, seu caráter vivo e atual, como elemento que emerge de um grupo e tem a capacidade de uni-lo. Como construção intencional, para cumprir a função da coesão do grupo, passa por constantes atualizações, i.e., "manipulações”.

A grande contribuição de Nora à atualização do conceito de Memória está em diferenciar Memória e História, que também é um exercício de Halbwachs (2003, p. 100), ao afirmar que "memória coletiva" não se confunde com a história, e julga a expressão "memória histórica" não muito feliz porque associa dois termos que se opõem "em mais de um ponto”. Já para Nora (1993, p. 9), “longe de serem sinônimos”, tudo opõe os dois termos.

Michael Pollak (1989) analisa a visão de Halbwachs, de abordagem durkheimiana, que enfatiza a força quase institucional da memória coletiva, durável, contínua e estável, na qual não se vê uma imposição ou uma forma específica de dominação. Pelo contrário, Halbwachs acentua as funções positivas desempenhadas pela memória comum, de reforçar a coesão social, pela adesão afetiva ao grupo, clara na sua expressão “comunidade afetiva”. Entre os pontos de referência que estruturam nossa memória e que a inserem na memória da coletividade a que pertencemos (HALBWACHS, 2003), “incluem-se os monumentos, esses lugares de memória analisados por Pierre Nora, o patrimônio arquitetônico e seu estilo, [...], as paisagens, as datas e personagens históricas de cuja importância somos incessantemente relembrados" (POLLAK, 1989, p. 3). Assim, afirma Pollak (1989, p. 3) que: "Na tradição europeia do século XIX, em Halbwachs, inclusive, a nação é a forma mais acabada de um grupo, e a memória nacional, a forma mais completa de uma memória coletiva".

A aproximação do conceito de memória ao de nação e ao de memória nacional é a grande contribuição que Pollak traz a este estudo, visto que a caracteriza como um campo de disputa. Numa perspectiva construtivista, o autor impõe uma inflexão ao conceito, pois "não se trata mais de lidar com os fatos sociais como coisas, mas de se analisar como os fatos sociais se tornam coisas, como e por quem eles são solidificados e dotados de duração e estabilidade" (POLLAK, 1989, p. 4). Pelo movimento da Nova História, lembra o autor o papel da história oral ao ressaltar a "importância das memórias 
subterrâneas, como parte integrante das culturas minoritárias e dominadas, que se opõem à memória oficial, no caso a memória nacional (POLLAK, 1989, p. 4).

As duas funções essenciais da memória comum para Pollak são: manter a coesão interna e defender as fronteiras daquilo que um grupo tem em comum, que no caso de Estados é o território. Nesse aspecto, Pollak considera adequado usar a expressão de Henry Rousso, "memória enquadrada", que julga um termo mais específico que "memória coletiva", e a transforma para seu uso em "trabalho de enquadramento" da memória, que para ele se alimenta do material fornecido pela história, reinterpretando incessantemente o passado, em função de combates do presente e do futuro ((POLLAK, 1989, p. 9).

Além de uma produção de discursos organizados em torno de acontecimentos e de grandes personagens, os rastros desse "trabalho de enquadramento" são os objetos materiais: monumentos, museus, bibliotecas etc. A esse rol, o autor acrescenta o filme, que tem um papel crescente na formação e reorganização, i.e., no enquadramento da memória, por sua capacidade de captar as emoções. ${ }^{1}$

Conforme sinalizado por Pinto e Farias (2012, p. 7), o âmbito dos estudos da Memória Social “é um campo de estudos que tem seu advento no século XX e, portanto, está ancorado no bojo das reflexões produzidas sobre questões que emergem no cenário dos acontecimentos desse século". Assim, o "trabalho de enquadramento da memória" nacional é percebido no Brasil, através da preocupação em se construir uma narrativa que explique a origem do povo brasileiro, i.e., a construção de uma narrativa que permita aos cidadãos se enxergarem nela, visto que o que está em jogo na memória é também o sentido da identidade individual.

A Era Vargas investiu fortemente na formação cívica da população brasileira. $\mathrm{Na}$ busca da centralização política e administrativa do Estado, diversas políticas foram implantadas, como: unificação do currículo escolar nacional e a ação de propaganda e censura do DIP (Departamento de Imprensa e Propaganda). Tais ações visavam enfraquecer os estados, que na Primeira República eram preponderantes. No contexto mundial, a ideologia fascista influenciava o mundo americano e europeu, e se

\footnotetext{
${ }^{1}$ Sobre projetos culturais varguistas, ler Fraga (2012).
} 
disseminava, tendo como princípio a superioridade do Estado às do indivíduo e da sociedade; a autoridade seria o caminho para forjar os laços nacionais e construir a unidade, promovendo para isto o afastamento das discordâncias, discussões e críticas. ${ }^{2}$

Na formação dos Estados Nacionais, trabalha-se numa dimensão cívico-patriótica educativa; e só se trabalha nessa dimensão atingindo os sentimentos. Nasce-se filho de uma família, mas não se nasce brasileiro, isto é, o Patriotismo não nasce espontaneamente; precisa ser aprendido. Nessa lógica, afirma Catroga (2010), o Estado Nacional constrói o sentimento de Pátria, porque para ele é desejável que a Nação seja uma grande Pátria, e não somente composta por cidadãos que obedeçam às leis. Por esta razão, em concordância com Anderson (1989), para o autor é relevante fazer emergir o ideal patriótico porque pela Pátria se morre, mas não pela Nação, ou muito menos pelo Estado; e essa fidelidade garante o bem-comum, a ideia de felicidade.

É nesse sentido que adquire relevância a concepção de cultura escolar, envolvendo saberes a ensinar, condutas a inculcar, e um conjunto de práticas que permitem a transmissão de saberes (JULIA, 2001). As novas correntes historiográficas filiadas à História Cultural permitem um reexame das relações entre a educação e a cultura, indicando a necessidade de uma acurada atenção aos processos internos da escola, que guardam estreitas relações com o universo social e cultural. Práticas escolares de natureza cívico-patrióticas, como: os batalhões infantis, o escotismo escolar e as comemorações cívicas, são formas pelas quais a escola contribuiu para a consolidação do projeto político-ideológico de construção da nacionalidade brasileira (SOUZA, 2000).

A civilização e o progresso do país eram os objetivos maiores dos projetos que visavam difundir o patriotismo, constituindo-se nos principais parâmetros da "grandeza da pátria", e tinha como alvo principal a infância brasileira, alcançada pela literatura cívica, como evidencia Patrícia Hansen (2007), tanto quanto pelas comemorações cívicas, quando ganhava aspecto mais requintado e coletivo o "trabalho de enquadramento da memória".

Ao serem analisados documentos da década de 1930 do acervo do Centro de Memória Ferreira Vianna, instituição pesquisada pela autora, foram localizados registros

\footnotetext{
${ }^{2}$ Ditaduras inspiradas nos ideais fascistas eram denominadas Estado Novo, como em Portugal e Espanha.
} 
referentes à implantação de um projeto que atendia a este fim, no qual emergem os sujeitos históricos da instituição: alunos, inspetoras, professores, diretor. Visto que os documentos são fragmentos, indícios do passado, adota-se como referencial teóricometodológico o paradigma indiciário de Carlo Ginzburg (1989), buscando através dos indícios e das pistas deixadas pelos homens de outros tempos elaborar uma versão do passado, unir fios de uma trama social, em que agentes e sujeitos históricos eram portadores de projetos de vida que se entrelaçavam.

\section{A agência do diretor José Piragibe na implantação do projeto Escola Cidade}

O diretor do Instituto Ferreira Vianna, José Piragibe, teve o privilégio ${ }^{3}$ de vivenciar o marco histórico da "Crise de 1929" e da "Revolução de 30", estando sob o comando de quatro diretores da diretoria de Instrução Pública do Rio de Janeiro, então Distrito Federal, no período de seu mandato que se iniciou em 14 de fevereiro de 1929 e findou em setembro de 1933.

Com a intervenção no Distrito Federal, após a "Revolução de 30", foi indicado ao cargo de Diretor Geral de Instrução Pública alguém que se contrapusesse aos ideais de Fernando de Azevedo, Diretor de Instrução Pública no período de 1927 a 1930. Assim, foi nomeado o professor Osvaldo Orico, mas poucos dias depois foi substituído pelo inspetor escolar do Distrito Federal, Raul de Faria, que no pouco tempo em que esteve à frente da Diretoria, promoveu investigações e inquéritos para apurar possíveis irregularidades da administração Fernando de Azevedo. Anísio Teixeira, o quarto diretor geral no mandato de José Piragipe, foi nomeado a partir de 1931, quando retoma e aprofunda a Reforma Fernando de Azevedo.

Segundo Paulilo (2009), na capital da República, Carneiro Leão (entre 1922 e 1926), Fernando de Azevedo (de 1927 a 1930) e Anísio Teixeira (a partir de 1931 até 1935) ocuparam o posto-chave da administração escolar na cidade: a direção da Instrução

\footnotetext{
${ }^{3}$ Usa-se aqui a expressão "privilégio" não para enaltecer o momento histórico, mas pelo fato de um diretor de uma instituição educacional, num curto mandato, ter vivenciado uma parte importante da história do Brasil, tendo em sua rede de relacionamentos sociais e profissionais, personagens como Vargas, Capanema, Jônatas Serrano, Anísio Teixeira, Fernando de Azevedo, cujos feitos hoje são reinterpretados no campo da pesquisa histórica.
} 
Pública. Em que pesem diferenças e especificidades entre os seus projetos reformadores, saúde, moral e trabalho eram os três pilares principais em que se assentava a convicção a respeito da importância da educação nos anos de 1920 (CARVALHO apud PAULILO, 2010), e por continuidade de ações, também nos anos iniciais de 1930.

Um Ofício do Diretor Geral Raul de Faria, datado de 13 de julho de 1931, foi enviado ao Instituto Ferreira Vianna, solicitando com a máxima urgência diversas informações relativas ao período de 01.01.1930 a 30.06.1931:

a) Quantos alunos foram matriculados nos diversos cursos, inclusive os que passaram dos anos anteriores;

b)Quantos alunos novos foram matriculados em cada curso;

c) Quantos alunos foram eliminados e a causa da eliminação;

d)Quantos alunos passaram para outros estabelecimentos municipais de ensino;

e) Quantos alunos foram promovidos e as condições em que foram realizadas essas promoções;

f) Qual a despesa anual do estabelecimento;

g)Quaisquer outras informações que julgueis úteis para o relatório que deverei apresentar, com brevidade, ao Sr. Interventor Federal. ${ }^{4}$

A resposta a este documento, elaborada pelo diretor José Piragibe consistiu num verdadeiro relatório que permite tomar-se ciência de algumas práticas promovidas pelo Instituto, angústias vivenciadas pelo diretor com relação às necessidades materiais da instituição, bem como perceber pontos de tensões entre seus sujeitos no período em questão.

José Joaquim Ferreira da Costa Piragibe era figura de destaque no magistério secundário. Bacharelou-se em Letras em 1896 pelo Imperial Collégio de Pedro II e Gynnasio Nacional, onde seu pai Alfredo Piragibe fora diretor do Internato nos anos de 1891 e 1892; ingressou na Faculdade de Medicina e Pharmácia do Rio de Janeiro, onde formou-se em História Natural. ${ }^{5}$ Acumulou vasta experiência no magistério privado, nos Colégios São Bento e Paula Freitas, onde ainda como estudante, lecionava História

\footnotetext{
${ }^{4}$ Ofício recebido ${ }^{\circ}$ 262, de 13.07.1931. Centro de Memória Ferreira Vianna.

${ }^{5}$ Em trabalho anterior, a autora deduzira que José Piragibe tivesse se formado médico, devido a ter estudado na faculdade de Medicina e Pharmacia, porém, ao pesquisar em fontes do Colégio Pedro II, constatou que sua formação foi em História Natural, que permitia lecionar à época: Química, Física e Biologia.
} 
Natural (Física, Química e Biologia) e Geografia. Em 1925, concretizou-se o sonho de qualquer professor da época: foi nomeado para reger interinamente a cadeira de Física do Internato do Colégio Pedro II. ${ }^{6}$ Em 1929, por influência de amigos como Jônatas Serrano, assumiu a direção do Instituto Ferreira Vianna, e em 1933 a direção do Instituto João Alfredo, até 21 de janeiro de 1940, quando faleceu após mal súbito aos 62 anos de idade. Assim se expressa Jônatas Serrano, após sua morte, deixando claro ter sido um educador sem maiores pretensões políticas, mas que só ganharia reconhecimento e influência se ocupasse cargos oficiais:

Não fossem alguns amigos que se impacientavam de vê-lo só a exgotarse no magistério particular sem garantias, mal remunerado e sem fama, não fosse a intervenção de leais e gratos colegas que o desejavam ver em postos de maior influencia, onde patenteasse as suas excepcionais qualidades de educador, e talvez Piragibe nunca houvesse exercido cargos oficiais. Chamado na administração Antonio Prado, por Fernando de Azevedo, à direção da Escola Ferreira Viana, aí se revelou o diretor-pai, se assim é lícito dizer. Cada um daqueles pobres órfãos tinha nele um verdadeiro protetor, com paternais cuidados, e a tal ponto que uma vez Ihe dissemos em palestra: - Você agora tem trezentos filhos... (SERRANO, 1940) ${ }^{7}$

Embora a maior parte das informações solicitadas no ofício do diretor Raul de Faria se referisse a aspectos quantitativos dos alunos, o diretor Piragibe dedica grande parte de seu relatório a descrever diversas atividades desenvolvidas pela instituição, e aproveita o ensejo para refazer reivindicações anteriores. Inicia com a descrição das condições em que se encontra o edifício, para que se verifique a "necessidade de obras urgentes", conforme ofícios já enviados anteriormente, desde 1929, quando “foram solicitados os consertos mais necessários". As vinte linhas seguintes não só ratificam as solicitações, como também contêm suas sugestões para a melhor adequação das instalações físicas com o menor custo possível, como por exemplo, a divisão de uma

\footnotetext{
${ }^{6}$ Livro de nomeações de funcionários, docentes e administrativos: 1921 - 1938 (Colégio Pedro II Internato). Arquivo do Colégio Pedro II, Centro do Rio de Janeiro.

${ }^{7}$ Fonte: Recorte de jornal sem identificação, s/d. Arquivo pessoal da família.
} 
grande sala onde ocorriam aulas de duas turmas ao mesmo tempo, com uso de tabiques, e não tijolos. ${ }^{8}$

No tópico seguinte do relatório é expressa a finalidade da instituição: "preparar os alunos que se destinam ao curso das escolas profissionais", onde era oferecido o curso primário por professoras adjuntas e substitutas, e contava-se com um professor de trabalhos manuais (em massa, madeira, metal etc). Cita que a idade exigida para ingresso é entre 7 e 9 anos e discorre sobre a transferência para o Instituto João Alfredo (antigo Asilo de Meninos Desvalidos) para os que tivessem condições ao completarem 13 anos. Relembra que em 1930 o diretor geral Raul de Faria permitiu que os alunos do $4^{\circ}$ ano que haviam atingido a puberdade pudessem ser transferidos para o curso de adaptação lá criado: "Tal medida veio beneficiar muitos alunos, que doutro modo teriam de ser excluídos sem poderem continuar o curso profissional".

Dentre outros assuntos voltados para as práticas pedagógicas da instituição (como por exemplo, aulas de canto), comenta em tom meio queixoso que os mestres de Avicultura, Horticultura e Apicultura da Escola Visconde de Mauá9 visitaram o Instituto, traçaram o programa que seria seguido e combinaram o horário, mas não puderam iniciar as atividades porque era necessário efetuar algumas obras. Sobre a Enfermaria, desabafa o diretor:

É fácil observar que nas diversas reformas de ensino o Instituto Ferreira Viana costuma ficar quase completamente esquecido... Uma das provas de asserto é este facto: a enfermeira do instituto é de quadro de pessoal subalterno! É uma senhora, com o ordenado de 250\$000, obrigada a permanecer no instituto dia e noite, apenas com uma folga por semana e sem ter quem a substitua. ${ }^{10}$

Apesar do pronto atendimento prestado pela Clínica Oscar Clark que funcionava em prédio vizinho ao Instituto, a crescente demanda de crianças internadas carecia de uma enfermaria "provida de uma enfermeira competente". Menções como esta demonstram o comprometimento e zelo do diretor José Piragibe

\footnotetext{
${ }^{8}$ Ofício expedido $n^{\circ}$ 146, de 21.07.1931.

${ }^{9}$ Escola ainda hoje existente na Rede FAETEC, no bairro de Marechal Hermes.

${ }^{10}$ Ofício expedido $n^{\circ}$ 146, de 21 de julho de 1931, p. 5. Centro de Memória Ferreira Vianna.
} 
para com os propósitos assistenciais e educacionais propugnados para a instituição no início do governo Vargas. Seu cargo “em comissão" não o inibia de cobrar incessantemente das autoridades competentes melhorias estruturais e de pessoal, para que as crianças sob os seus cuidados contassem com os recursos necessários à formação exigida para um futuro trabalhador: saúde, instrução elementar e destreza técnica.

Parte especial do relatório do diretor é dedicada à descrição de questões disciplinares no Instituto Ferreira Vianna, que se agravavam com o fato da inspetora chefe Sra. Cesalpina Ramos, acumular as funções de ecônoma" e almoxarife. "Seria de grande vantagem para o Instituto", argumenta o diretor, "diminuir os encargos da Inspetora Chefe".

Sempre em tom respeitoso, no "uso privado" de sua razão pela função que ocupava na instituição (FOUCAULT, 2000), mas não deixando de expressar seus anseios, Piragibe afirma no relatório que o trabalho das inspetoras era excessivo e constantes as reclamações que estas lhe dirigiam, sendo apenas 8 inspetoras para 300 alunos, na sua maioria de 7 a 9 anos. Apesar de ter recebido autonomia para nomear inspetoras substitutas no caso de faltas ou licenças médicas, declara que

persiste, porém, o trabalho demasiado, e as queixas contínuas. Alegam as queixosas que fizeram o mesmo concurso das inspetoras de externato e que estas trabalham apenas poucas horas por dia, não trabalham às quintas feiras, e têm as férias completas. As queixas como bem sentis, têm toda a razão de ser. Não vejo, entretanto, possibilidade de aumentar, no momento, o número de inspetoras, de modo que haja duas turmas, que trabalhem em dias alternados. ${ }^{12}$

Para solucionar o problema das queixas sobre as concursadas que trabalhavam em externatos e as que trabalhavam em internato, o diretor Piragibe sugere que sejam criados dois quadros de inspetoras: um para externato e outro para internato, e que seria prudente que uma vez nomeada, a inspetora de internato só pudesse ser considerada efetiva depois de dois anos de estágio. Desta forma, percebe-se que o diretor não se

\footnotetext{
${ }^{11}$ Ecônomo: aquele que se encarrega da administração de uma casa, de um internato, de um hotel; despenseiro; mordomo.

${ }^{12}$ Ofício expedido $n^{\circ}$ 146, de 21 de julho de 1931, pp. 4-5. Centro de Memória Ferreira Vianna.
} 
limita apenas a relatar os problemas e pedir providências, mas também sugere alternativas possíveis para solucioná-los. Isto é, ele é agente nesse processo, atuando na melhoria das condições oferecidas pela instituição a esses meninos e funcionários, e assim buscando modificar o rumo de suas histórias. Em janeiro de 1931, o instituto contava 50 funcionários, dos quais 34 eram administrativos e 16 docentes. O diretor também declara que a falta de serventes "tem levado os alunos a realizar certos serviços", que do seu ponto de vista, seriam inadequados para a sua idade:

Considerando a idade dos alunos aqui internados, posso afirmar que o Instituto Ferreira Viana é o único em que os alunos não podem, nem devem realizar certos serviços. Quero referir-me neste momento aos serviços pesados, e aos serviços de escrita. Encontrei meninos fazendo serviços incompatíveis com a idade deles: limpeza de refeitório, lavagem de janelas etc., trabalho que tem de ser feito com a presença constante da inspetora. Não me foi possível ainda obter mais um servente para aqueles serviços. ${ }^{13}$

Revela o diretor Piragibe em seu relatório que, por sugestão do Diretor Geral Raul de Faria, iniciou-se no ano de 1931 a instalação da "Escola Cidade" no Instituto Ferreira Vianna. O Projeto Escola Cidade consiste na criação de departamentos de serviços no Instituto, retratando uma cidade, cujos habitantes e servidores são os próprios alunos. Devido ao momento histórico da divulgação dos ideais da escola nova, acredita-se que visava desenvolver a autonomia nos alunos através de métodos ativos, o que não extingue o seu caráter disciplinador, conforme ofício interno do diretor aos funcionários, datado de abril de 1931. O Instituto Ferreira Vianna seria a primeira instituição a testar o projeto no Brasil, visto que já funcionava nos países ditos "mais cultos", segundo Piragibe.

Sobre este projeto pioneiro, o diretor menciona as dificuldades de se adaptar ao nosso meio "o que sobre o assunto se faz no estrangeiro", problema este agravado pela “inexistência de outra instituição que tenha adotado tal processo" no Brasil. Porém, apesar do pioneirismo do projeto, “depois de preparar melhor o espírito do pessoal

\footnotetext{
${ }^{13}$ Ofício expedido n 146 , de 21 de julho de 1931, p. 6. Centro de Memória Ferreira Vianna.
} 
docente e administrativo", o diretor achou prudente considerar a idade e a cultura dos alunos, e chegou à conclusão de que a primeira necessidade do grupo era a criação de uma Polícia. Assim, foi criada a Guarda Civil (Fig. 1), com as "autoridades" eleitas pelos próprios alunos.

\section{Figura 1 - Guarda Civil do Instituto Ferreira Vianna}

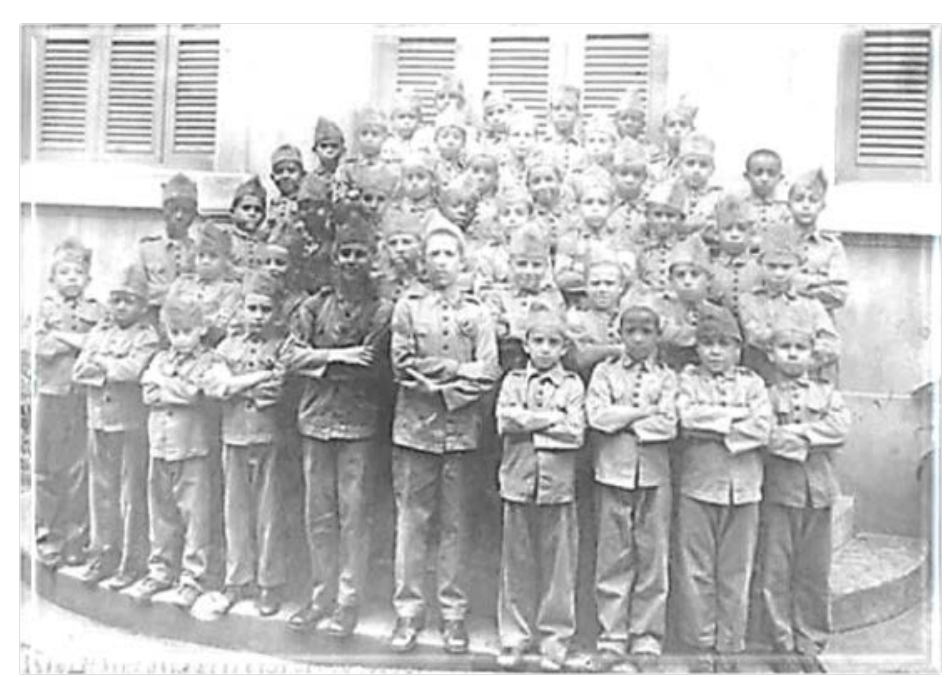

Fonte: Acervo do Centro de Memória Ferreira Vianna. Ano: 1931.

A Guarda Civil no Instituto foi fundada em 22 de abril de 1931, segundo ata manuscrita, onde estão registrados os nomes dos membros eleitos, e seus respectivos números. Foram eleitos 1 chefe, 1 subchefe, 16 inspetores e 31 guardas. Segundo o regulamento, nova eleição deveria ocorrer a cada três meses. Todos possuíam 1 emblema mas, para distingui-los hierarquicamente, o chefe possuía 6 divisas, o subchefe 4 divisas, os inspetores 2 divisas e os guardas 1 divisa. ${ }^{14}$

Pelo mesmo processo foram criados o Departamento das Diversões, o Corpo de Saúde (Fig. 2), o Departamento do Trabalho (Fig. 3) e a Repartição dos Correios.

\footnotetext{
${ }^{14}$ Fonte: Organização da Guarda Civil. Abril/1931, documento datilografado.
} 
Figura 2 - Corpo de Saúde

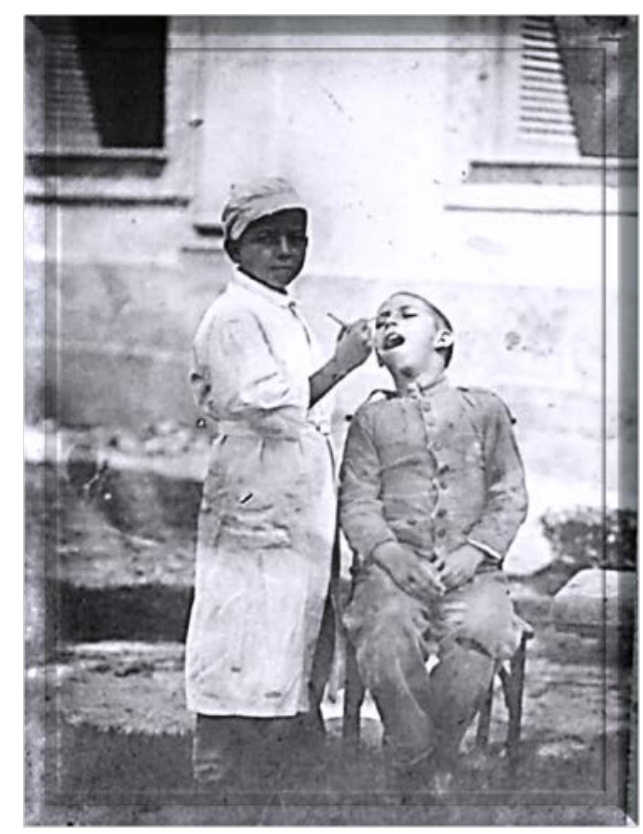

Fonte: Centro de Memória Ferreira Vianna. Ano: 1931.

Um guarda socorrendo um aluno com dor de dente. Cabia ao Corpo de Saúde verificar diariamente o asseio dos dentes, das unhas, da roupa e do calçado dos menores, auxiliando o serviço da enfermaria e do gabinete dentário.

Figura 3 - Departamento do Trabalho

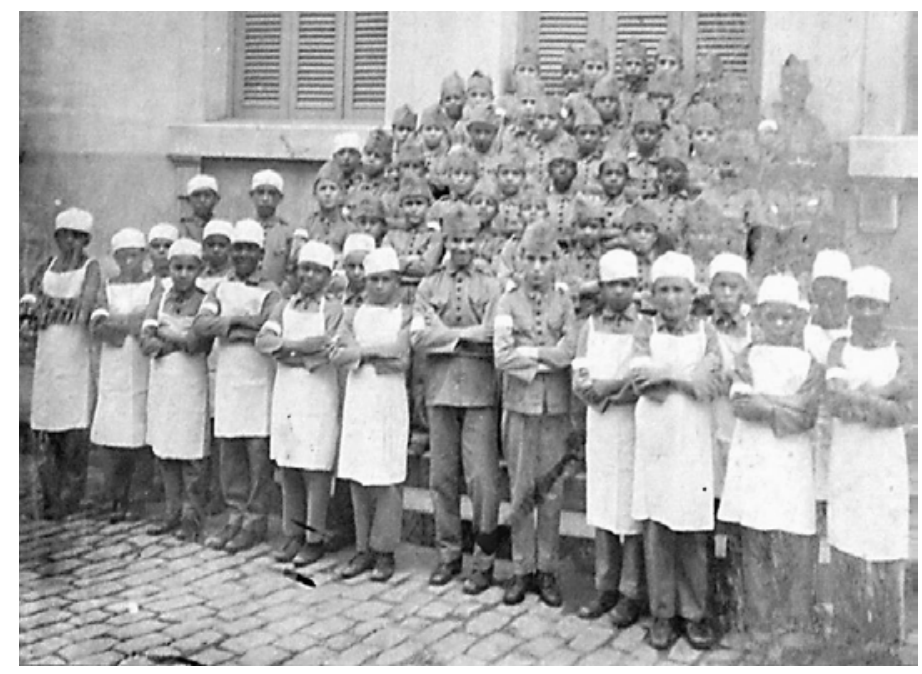

Fonte: Centro de Memória Ferreira Vianna. Ano: 1931.

Ao centro, o chefe e o subchefe; ao seu lado, de gorro e avental, os alunos escalados para o serviço de refeitório. O Departamento do Trabalho era responsável por fiscalizar os alunos escalados para os diversos serviços do Instituto: servir refeições, limpar o refeitório, varrer as dependências, lavar os sanitários, etc. 
No Projeto Escola Cidade, cada departamento tinha os seus chefes, fiscais e auxiliares. O diretor prevê em seu relatório, futuramente, a eleição de um prefeito e um Conselho Consultivo devido à complexidade do sistema. E realmente houve a eleição do prefeito em setembro do mesmo ano: Mário Mexias, que configura no centro da foto das “altas autoridades" do Instituto (Fig. 4).

Figura 4 - As “Altas Autoridades”

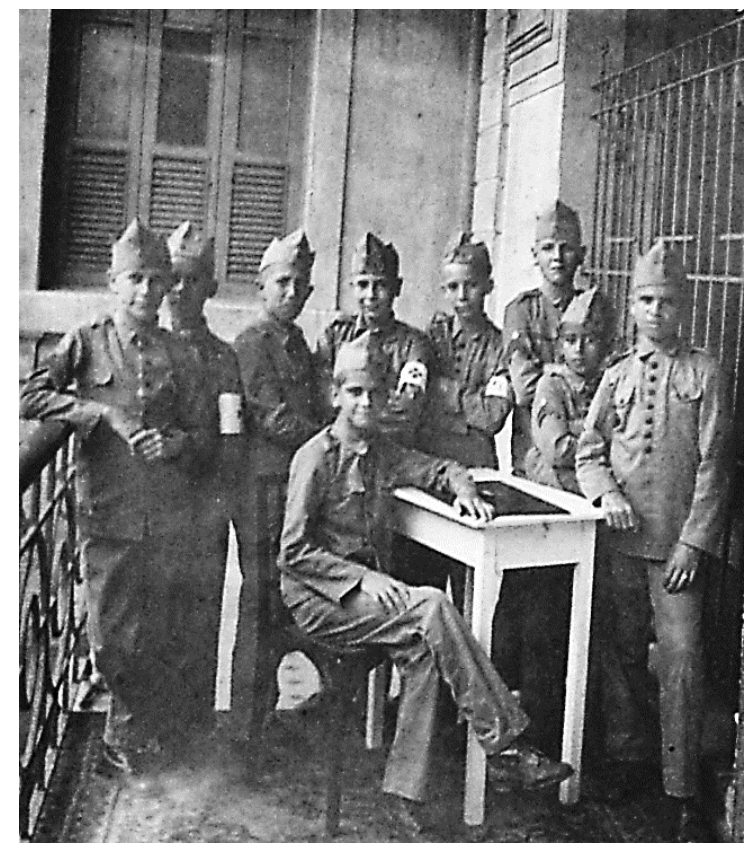

Fonte: Centro de Memória Ferreira Vianna. Ano: 1931.

Conforme designação do álbum existente no acervo com as fotos originais: sentado, o Prefeito Mário Mexias; em pé, da direita para a esquerda: o diretor do Departamento do Trabalho, o ajudante da Guarda Civil, o ajudante do Departamento de Diversões e o diretor deste departamento, o secretário do Corpo de Saúde, o ajudante da Guarda Civil, o chefe do Corpo de Saúde e o Chefe de Polícia.

Com relação à Guarda Civil, as "Zonas de Policiamento” definidas pelo diretor Piragibe seriam assim distribuídas:

A) Recreio - 1 guarda para as privadas e a bica; 1 para o portão; e 2 para as passagens. Por ocasião das formaturas todos os guardas auxiliarão o serviço.

B) Dormitórios superiores - 1 guarda.

C) Recreio coberto, dormitórios da parte térrea e terrenos ao redor da cozinha - 1 guarda.

D) Alameda, jardim, terreno dos fundos da escola - 1 guarda. 
E) Secretaria -1 inspetor..$^{15}$

O chefe, o subchefe e os inspetores gozavam de maior privilégio que os guardas quanto às saídas, que podiam ser quinzenais ou mensais; para os guardas, eram de dois em dois meses. Os privilégios decorrentes da hierarquia ficam mais evidentes no parágrafo $7^{\circ}$ do mesmo documento: "O chefe, o subchefe e os inspetores não devem ser escalados para fazer, e sim, para dirigir serviços".

Quanto à conduta dos membros da Guarda Civil, havia a preocupação de que não se envolvessem em embates frontais. Segundo recomendação, deveriam "falar o menos possível; falar o mais baixo que fosse possível; e nunca discutir com o transgressor, nem tocá-lo". As "más condutas" dos alunos eram registradas diariamente pelo chefe: comportar-se mal no refeitório, desobedecer aos superiores, entrar em salas de aula sem ser chamado, retirar objetos das oficinas etc. As punições eram: desmanchar e fazer o dormitório durante 5 dias, ficar isolado uma semana, ficar sem recreio durante uma semana, escrever de 200 a 500 vezes a falta que cometeram por cinco dias ${ }^{16}$. É importante ressaltar que era o chefe da Guarda Civil quem definia qual seria a punição a ser recebida pelos “transgressores", sendo ele um menino como os demais.

\section{O Livro das Partes Diárias das Inspetoras - revelando tensões e conflitos}

Tenho a certeza de que não escapará ao espírito esclarecido das senhoras Inspetoras e demais funcionários deste Instituto a vantagem deste processo disciplinar, já adotado com os melhores resultados por muitos países cultos. Vamos fazer uma experiência. Esperamos o concurso de todos. Ass.: O diretor José Piragibe. ${ }^{17}$

Devido a este comunicado interno, suspeita-se que o Projeto Escola Cidade causou certo estranhamento aos funcionários do Instituto Ferreira Vianna, tendo em vista a

\footnotetext{
${ }^{15}$ Fonte: Organização da Guarda Civil. Abril/1931, documento datilografado.

${ }^{16}$ Fonte: “Partes do Prefeito", 28.11.1931 (documento manuscrito e assinado por Mário Mexias).

${ }^{17}$ Ofício interno, abril/1931. Acervo do Centro de Memória Ferreira Vianna.
} 
autonomia dada aos alunos. Apreensivo com o novo, mas comprometido com a plena realização dos propósitos educacionais idealizados pela Diretoria Geral de Instrução, o diretor José Piragibe solicita aos funcionários que considerem as vantagens desse "processo disciplinar" que já era adotado com bons resultados em muitos países "cultos".

Trabalha-se com a hipótese de que o relacionamento entre os alunos membros dos diversos Departamentos criados pelo Projeto Escola Cidade e as inspetoras era permeado por conflitos, tensões e constrangimentos, especialmente entre os que interagiam diretamente com os menores com relação ao trabalho e à disciplina, visto serem as inspetoras os agentes ativos nessas demandas. Para confirmar essa hipótese, recorreu-se aos registros de uma valiosa fonte: o Livro das Partes Diárias das Inspetoras, onde há registros exatamente desse momento da história do Instituto. Este era um meio do diretor José Piragibe acompanhar os acontecimentos referentes aos alunos, principalmente os de “maus procedimentos". O livro contém 200 páginas pautadas e numeradas, com utilização da frente e do verso; tem capa dura vermelha, bastante espessa e pesa cerca de dois quilos. Há nele registros diários de 02 de dezembro de 1931 a 28 de setembro de 1933. Setembro foi o último mês de mandato do diretor José Piragibe; e o último registro do livro coincide com a sua saída.

O método utilizado para análise dos registros do livro consistiu na transcrição dos registros para uma planilha, com data, página e nome da inspetora que fez a "parte", ou o diretor. Ao serem relidas, as "partes" foram agrupadas, a fim de quantificar e categorizar a totalidade dos acontecimentos, e assim chegar-se a algumas conclusões iniciais a respeito das práticas escolares da instituição nessa fase em que a Guarda Civil e as diversas Diretorias formadas pelos alunos foram mais atuantes. Nesse processo analítico, Thompson nos permite pensar como o processo de escolarização, as culturas escolares não são um pressuposto, mas o processo e o resultado das experiências dos sujeitos, dos sentidos construídos e compartilhados ou disputados pelos atores que fazem a escola (FARIA FILHO e BERTUCCI, 2009).

Todos os dias eram feitos registros e, no caso de não haver acontecimentos a registrar, as inspetoras anotavam a expressão "Nada houve” e assinavam na linha abaixo. Ao final da folha, a inspetora chefe Cesalpina Ramos informava se havia alguma inspetora 
folgando ou faltando, ou se alguém não havia dado "parte", e assinava após escrever o nome da escola e a data. Abaixo da inspetora chefe, assinava o diretor José Piragibe, após ler os registros e fazer observações, caso necessário. Em alguns períodos não se observa registros, como nos meses de janeiro e fevereiro, provavelmente devido às férias escolares; o que nos permite pensar que nesses meses as crianças não permaneciam no Instituto.

Dentre os 350 registros feitos no período, 111 são de encaminhamentos ao médico (de grupos de alunos, não de indivíduos); 25 grupos são de encaminhamentos à enfermaria; 10 grupos são de encaminhamentos ao dentista; há 56 comunicados entre a inspetora chefe e as inspetoras ou do diretor para as inspetoras; das 102 anotações de "maus procedimentos" inserem-se desobediências, respostas malcriadas, atos indecentes, xingamentos, provocação de desordem, barulho no dormitório, danificação de objetos do instituto, lançamento de pedras nas casas vizinhas ou no recreio, furtos e 5 fugas do Instituto; 7 anotações das inspetoras denunciam os alunos que abandonam o serviço; 4 se referem a alunos suspensos por faltas graves, não especificadas; 28 registros são de agressões entre os alunos, dos quais 6 são aos chefes dos departamentos ou guardas; em 2 registros são destituídos de seus cargos o diretor e o chefe do Trabalho, por desmentirem ou questionarem as inspetoras. Um fato interessante é que os alunos são sempre identificados por números, nunca pelos nomes, lembrando as práticas de um sistema prisional. Foi possível fazer a relação número/nome nesta pesquisa devido à existência de uma relação datilografada, com os nomes dos 300 menores matriculados no Instituto Ferreira Vianna no ano de 1930, com número, nome completo e data de nascimento. ${ }^{18}$

Os registros do livro das inspetoras possibilitam a problematização a partir de diversas questões, porém, devido aos limites deste artigo, serão destacadas algumas "ocorrências" que retratam os constrangimentos e rejeições pelos quais passaram os membros da Guarda Civil, do Corpo de Saúde e da Diretoria do Trabalho, visto que de alguma forma exerciam poder sobre os alunos, para os obrigarem ao trabalho, para cobrar-Ihes o "asseio" ou inibirem sua liberdade; resultando em resistência.

\footnotetext{
${ }^{18}$ Ofício Expedido n²4, de 28.01.1931.
} 
Os indícios demonstram que era recorrente a falta de obediência aos chefes, e que os casos mais graves de insubordinação eram registrados com detalhes, a fim de ser aplicada a devida punição. A intervenção dos guardas se fazia necessária para manter o silêncio, garantir o comportamento adequado no refeitório e no banho, bem como fiscalizar os serviços de limpeza e arrumação feitos pelos alunos. No exercício de sua função, alguns guardas recebiam "tratamento grosseiro" por parte dos outros menores, como é o caso do chefe Aristides Macedo, de número 138; acontecimento registrado pela inspetora Oda Correa em 27 de abril de 1932. No dia seguinte, o tratamento grosseiro evoluiu para agressão física:

Os menores de $\mathrm{n}^{\circ} 89,289,230$ e 174 continuaram com péssimo comportamento. Os três primeiros fugiram ontem diversas vezes do recreio e quando observados e privados do mesmo, responderam mal e ficaram gritando ser tal castigo uma injustiça; o último deles observado pelo chefe 138 investiu para ele e bateu-lhe bastante, fazendo-me ainda uma série de malcriações. ${ }^{19}$

O Diretor da Saúde, Haroldo José Domingos, também foi agredido por outro menor, que foi imediatamente “corrigido" pela inspetora Maria José “à vista” dos alunos:

O menor de $n^{\circ} 190$ às 6 horas da tarde, bateu na face do Diretor da Saúde (menor de $\mathrm{n}^{\circ} 2$ ) e, como eu o chamasse para castigá-lo, insultou-me à vista de vários meninos, de modo que, tive necessidade de agir com a máxima energia para evitar que ele continuasse. O mesmo menor declarou em altas vozes que irá arranjar a minha exoneração do cargo que ocupo. É necessário que isto não se repita. ${ }^{20}$

Recaía sobre os alunos da Guarda Civil e diretorias do projeto Escola Cidade grande responsabilidade pela disciplina dos alunos; os quais agiam autonomamente, sem a orientação devida das inspetoras. Seria essa falta de orientação decorrente do número reduzido de inspetoras ou seria uma atitude de resistência das mesmas? Devido à

\footnotetext{
${ }^{19}$ Inspetora Immaculada, Livro das partes diárias, 28.04.1932, p. 45 fr.

${ }^{20}$ Inspetora Maria José, Livro das partes diárias, 13.07.1933, p. 182 vs.
} 
proporção alunos/inspetoras (300/8), a primeira possibilidade é objetivamente aceitável; já a segunda, pode ser pensada a partir do registro que a Inspetora Chefe Cesalpina Ramos deixa no livro, solicitando às inspetoras que não deixassem a disciplina “exclusivamente entregue aos meninos", o que no seu entender era "um absurdo"; e que a elas cabia a fiscalização e orientação, porque elas também pertenciam ao grupo de educadores. $^{21}$

Percebe-se que as funções das inspetoras e as dos alunos da Guarda Civil e demais departamentos com relação à limpeza do Instituto e disciplina dos alunos se confundiam. Pela evolução dos registros, fica evidente uma medição de forças entre os dois grupos, e começam a ser reivindicados castigos para os chefes, de quem era exigido comportamento exemplar perante os demais alunos.

Já tendo conhecimento dos diversos constrangimentos vivenciados pelos Chefes, o diretor José Piragibe registra no livro recomendações sobre o serviço de conservação, asseio e limpeza do instituto, definindo as funções das inspetoras e dos guardas. Esclarece o diretor que o serviço deveria ser feito exclusivamente pelos alunos, dirigidos pelos chefes. Caberia às inspetoras instruir os chefes sobre o serviço a ser feito, fiscalizar o serviço depois de feito, e fazer aos chefes as recomendações necessárias "à perfeição do serviço". Recomenda ainda que todos os funcionários deveriam prestigiar os chefes e “dar-lhes autoridade" e que em hipótese alguma deveriam ser castigados na presença dos outros alunos. O chefe que não cumprisse o seu dever ou incorresse em falta grave, deveria primeiramente ser destituído do cargo, e depois então teria o castigo de acordo com a falta. ${ }^{22}$

As recomendações do diretor Piragibe dão pistas de que começaram a ocorrer punições aos chefes na frente dos demais alunos; porém, não foram localizados registros desse teor, possivelmente por não interessar sua revelação. Como afirma Foucault (2012), os registros, os documentos, têm a característica da redução; e além de não expressarem o que realmente ocorreu, trabalha-se com "cortes".

\footnotetext{
${ }^{21}$ Insp. Chefe Cesalpina, Livro das partes diárias, 19.06.1933, p.176 vs.

${ }^{22}$ Livro das partes diárias, 14.12.1932, p. 147 fr/vs.
} 
Observa-se que a vigilância das inspetoras sobre os guardas era constante, até sobre os termos que proferiam, como é o caso do registro da inspetora Immaculada, que pede “castigo severo” para os chefes Walter Canogia e Walter de Aguiar Alves:

\begin{abstract}
Os chefes de $\mathrm{n}^{\circ} 4$ e 200 que auxiliam a disciplina no $3^{\circ}$ dormitório, vêm de algum tempo para cá afastando-se de todas as regras de educação e moral, chegando a proferir na minha presença e na de seus colegas de turma, termos bem inconvenientes. Tal procedimento, por se tratar de chefes, foi por mim muito observado oportunamente e depois de muito aconselha-los aguardei melhor comportamento. Vejo entretanto que todos os meus esforços para que se corrigissem foram nulos e por esse motivo peço que lhes sejam dado um castigo severo. ${ }^{23}$
\end{abstract}

Os motivos de destituições de cargos estão diretamente relacionados à ameaça da perda de "autoridade" das inspetoras. Duas destituições são localizadas no livro: a do Diretor do Trabalho, $\mathrm{n}^{\circ}$ 230, por ter “desrespeitado" a inspetora D. Maria José (abril de 1933); e do Chefe do Trabalho, $n^{\circ} 82$, por ter desmentido na presença dos outros alunos a Inspetora Oda Menezes (agosto de 1933). Possivelmente se tratava do mesmo cargo, que fora ocupado por substituição deste àquele. O chefe anterior, havia sido destituído por ter desrespeitado a inspetora Maria José, mas não há detalhes sobre como se deu este "desrespeito". Seria mesmo motivo para destituição? Fato é que a inspetora continuou no encalço dele, e cinco dias depois de destituído, Maria José registra que este se tornava cada vez mais "insubordinável”, declarando que iria fugir do Instituto, a fim de conseguir com que saísse "nos diversos jornais tudo o que se passava ali", pois assim acreditava que cessariam os "abusos".

Os registros do Livro de Inspetoras reacendem interrogações sobre como se deu o processo de implantação do Projeto Escola Cidade no Instituto Ferreira Vianna, não revelados em relatórios e documentos oficiais. Levando em conta o princípio da totalidade e historicidade de todo fenômeno social, pode-se dizer com Thompson (1998) que entender um processo histórico é buscar, por meio das evidências históricas, apreender como homens e mulheres agem e pensam dentro de determinadas condições; homens e mulheres em sua vida material, em suas relações determinadas, em sua

\footnotetext{
${ }^{23}$ Inspetora Immaculada, Livro das partes diárias, 18.05.1933, p. 168 fr.
} 
experiência nessas relações, e em sua autoconsciência dessa experiência. Daí decorre a importância dos registros feitos por esses sujeitos históricos.

Com Thompson podemos refletir sobre o silenciamento imposto pelas inspetoras aos membros do Projeto Escola Cidade, que supostamente receberam autonomia para agir. Diante da pressão e opressão daquelas, estes procuravam lutar com os meios disponíveis para serem ouvidos, como foi o caso do Chefe do Trabalho destituído, que não tinha como contar a sua versão da história, e assim deixa indícios de que se sentia injustiçado. A forma de expressar seu descontentamento era tornar-se cada vez mais “insubordinável”, e fazer ameaças de que, para alcançar seus objetivos, iria acionar um mecanismo de comunicação de grande repercussão e temido pelo poder público: a imprensa. Este estudo não seguiu os seus rastros, a fim de buscar indícios de que o interno atingiu seu intento; porém, lembramos que outros mecanismos podem ter sido acionados pela inspetora ou pela instituição antes que o menino tivesse êxito como, por exemplo, o seu desligamento, que era previsto em regimento, no caso de desenvolvimento físico que pudesse prejudicar os de menor idade ou por completar treze anos, estando em condições de ser transferido para outras instituições de ensino profissional industrial ou agrícola. E caso houvesse recusa da família em receber o aluno, ou se não tivesse responsáveis, poderia ser entregue ao Juiz de Menores.

\section{Arquivos escolares - fontes preciosas para a história da educação ${ }^{24}$}

Os arquivos escolares têm por finalidade serem meio de prova de direito de pessoas ou da administração. Mas também têm função informativa para a administração pública, pois podem lhe oferecer informações, por exemplo, "da evolução do oferecimento do número de vagas, de repetência, evasão escolar etc." Para os historiadores, tais documentos são fontes para a História da Educação, manifestação ou representação da memória (BONATO, 2005, p. 197). Através desses acervos é possível conhecer as atividades administrativas e pedagógicas de transformação da educação ao longo do tempo, enfim, perceber a cultura escolar da instituição.

\footnotetext{
${ }^{24}$ Partes destas reflexões foram apresentadas pela autora em evento de Educação (Ver OLIVEIRA, 2013).
} 
Segundo Mogarro (2005), a cultura escolar é constituída por um conjunto de teorias, saberes, ideias e princípios, normas, regras, rituais, rotinas, hábitos e práticas; remetendo-nos às formas de fazer e de pensar, aos comportamentos sedimentados ao longo do tempo e que se apresentam como tradições, regularidades e regras, mais subentendidas que expressas, as quais são partilhadas pelos atores educativos no seio das instituições. Essa cultura constitui um substrato formado, ao longo do tempo, por camadas entrelaçadas, que importa separar e analisar. O exercício do arquivo tem um espaço importante nesse processo historiográfico de investigação sobre a cultura escolar, que sofreu forte influência das Reformas Educacionais das décadas de 1920 e 1930. Para Paulilo et al (1999, p. 203), as multiplicidades de elementos trazidas pela Reforma Fernando Azevedo (1927 - 1930), por exemplo, passaram a fazer parte da cultura e das práticas escolares:

Caracterizada por uma intensa renovação da materialidade escolar e dos métodos pedagógicos, a reforma Azevedo introduziu nas escolas novos objetos como, por exemplo, projetores de imagem fixa e em movimento, caneca, sabão, e escovas de dentes e ressignificou antigos, como tabuleiros de areia, vasilhas, tubos de ensaio, pretendendo transformar 0 ensino "de verbalista em ativo" e concorrendo para preservar condutas higiênicas, de forma a disciplinar gestos, olhares e corpos de alunos e alunas. $^{25}$

A ressignificação de objetos e métodos é percebida ao nos debruçarmos sobre os arquivos de escolas, embora em sua quase totalidade se encontrem em condições precárias de conservação. Conforme diagnóstico levantado por Ribeiro (1992), os arquivos escolares geralmente são precários. Cerca de dois terços dos espaços onde estão guardados os documentos são inadequados, devido à falta de ventilação e iluminação, excesso de umidade, poeira etc. Consequentemente, estão presentes na documentação poluentes atmosféricos, insetos, fungos, traças, entre outros problemas detectados e causadores do processo de destruição. Em grande parte dos arquivos, o acondicionamento dos documentos é feito em pastas, envelopes, encadernados, caixas

\footnotetext{
${ }^{25}$ PAULILO apud BONATO, 2005, pp. 199-200.
} 
de papelão; e também encontrados empilhados e sem nenhuma proteção. Em sua pesquisa, relata o autor, o acesso aos documentos muitas vezes era feito pela memória dos funcionários responsáveis, opção esta de muitos pesquisadores, ao se depararem com arquivos que se perderam ao longo do tempo por falta de preservação adequada.

Num processo de descarte, os primeiros documentos a serem eliminados de um arquivo escolar entendido como "morto", são os cadernos de alunos, planos de aula, diários de classe, considerados "lixo histórico". No entanto, são esses documentos que possibilitariam o estudo do cotidiano dessas escolas, numa perspectiva aberta pela Nova História. Aos historiadores da educação não bastam os documentos oficiais. As fontes orais, cadernos escolares, desenhos, antigos livros didáticos e atlas escolares, filmes, fitas cassete e fotos, também interessam (MEDEIROS, 2003). No seu conjunto, essas fontes de informação implicam ao investigador uma atitude necessariamente atenta aos contextos educativos e culturais em que foram produzidas e à seleção a que foram submetidas pelas gerações de atores sociais que as tutelaram, ocupando diferentes níveis de poder decisório sobre elas e sobre a sua preservação ou eliminação (MOGARRO, 2005).

A falta de preservação e conservação da documentação por parte das escolas constitui barreira ao processo de pesquisar em seus arquivos. Esta é uma problemática que precisa estar presente na pauta de discussão dos historiadores da educação, sobre a qual Souza (2013) levanta questões relevantes quando propõe a inserção do patrimônio escolar no campo mais amplo do patrimônio cultural. Para a autora, dentre os grandes temas em debate nesse campo atualmente estão: as tensões entre o particular e o universal, o público e o privado, os desafios postos pelo patrimônio imaterial, o papel da educação patrimonial, a banalização do patrimônio histórico pela conversão de seu valor de uso em valor econômico e as consequências de sua exploração pelo turismo e pela indústria cultural. Assim, a inserção do patrimônio escolar nesse debate público, político e especializado no campo da preservação, é necessidade urgente e um desafio a ser enfrentado.

A criação de museus e centros de documentação e memória, a realização de encontros científicos, as iniciativas de grupos de pesquisas de preservação da cultura material em instituições escolares e publicações relacionadas ao tema, representam âmbitos de atuação reveladores da importância da questão do patrimônio no campo 
educacional. No Brasil, tem-se assistido a sua rápida proliferação, conforme levantamento da Souza (2013), porém, a mesma alerta que é preciso avançar no que diz respeito ao debate político acerca da preservação desse patrimônio, bem como na reflexão do sentido das práticas de salvaguarda do patrimônio escolar. Assim, a autora propõe o uso do termo "patrimônio histórico escolar", o qual diz respeito à concepção do que seja o patrimônio relativo à educação e às práticas de conservação, referindo-se não somente ao tombamento de edifícios, mas à necessidade de proteção do acervo documental, museológico e bibliográfico e dos modos de fazer e praticar o ensino.

Uma das principais justificativas para a preservação do patrimônio cultural, prossegue a autora, é a sua relevância para a construção da identidade dos sujeitos, de suas relações com o tempo e o espaço e para a construção da memória. Analogamente, a preservação do patrimônio escolar reforça a importância da conservação da memória da escola, funcionando como ferramenta de reflexão sobre o significado da escola como instituição ao longo do tempo e os sentidos de sua atuação no presente.

Recuperar a história da escola pública através da valorização dos seus arquivos constitui uma forma de restauração da sua identidade e dignidade. Estes documentos, testemunhos do cotidiano da instituição escolar, constituem registros que foram produzidos "por instituições ou indivíduos singulares, tendo em vista não uma utilização ulterior, e sim, na maioria das vezes, um objetivo imediato, espontâneo ou não, sem a consciência da [sua] historicidade..." (ROUSSO apud GONÇALVES, 2008, p. 74). Nesse resgate, acredita-se que cumpre também à universidade o papel social de colocar os seus conhecimentos em prol da sociedade e da preservação da sua memória, como foi evidenciado nesta experiência de pesquisa.

\section{Considerações Finais}

As experiências vivenciadas pelos sujeitos do Instituto Ferreira Vianna durante a implantação do Projeto Escola Cidade, puderam aqui ser conhecidas a partir de fontes documentais de um arquivo escolar que, embora fragmentado, permite que estes sujeitos "esquecidos da história” tenham restituído o lugar a que têm direito na história 
da sociedade (RÉMOND, 2003). Destaca-se nesse contexto o importante papel desempenhado pelo diretor José Piragibe, como agente mediador entre as políticas do Estado e a integridade física, educacional e moral desses meninos.

Pertencer aos departamentos criados pelo projeto era motivo de orgulho para os alunos, sobretudo pelos privilégios que tinham em relação aos demais. O fardamento e as divisas, que os caracterizavam como organização militar, conferia-lhes status e prestígio; bem como nutria nestes um sentimento de fidelidade à nação em construção. Evidenciam-se também os papéis sociais, em que o trabalho braçal, de execução, é realizado pelos subalternos, pelos que não possuem poder, reproduzindo assim as relações da classe operária. O Projeto Escola Cidade, que conciliaria trabalho, educação e disciplina, foi promotor de transformações nas práticas escolares, moldou comportamentos e teve forte influência na construção dos sujeitos dentro da malha institucional, realizando assim um importante "trabalho de enquadramento da memória", conforme postulado por Pollak (1989).

Isso justifica a finalidade de se analisar documentos antigos e nos aventurarmos a desbravar arquivos considerados "mortos", "lixo histórico" (HEYMANN, 1997), pois quem sabe, "onde ele é mais opaco, talvez se consiga descobrir um sistema de significados estranho [diferente]? O fio pode até conduzir a uma pitoresca e maravilhosa visão de mundo..., [pois] sempre é possível fazer perguntas novas ao material antigo" (DARNTON, 1986).

\section{Referências}

ANDERSON, Benedict. Nação e consciência nacional. São Paulo. Ática, 1989.

Ata da eleição da Guarda Civil. 22.04.1931. Centro de Memória Ferreira Vianna (documento manuscrito, 2 páginas).

BONATO, Nailda. Arquivos escolares como fonte para a história da educação. Revista Brasileira de História da Educação, SBHE, v.00, n.00, p. 193 - 220, jul-dez. 2005

CATROGA, Fernando. Pátria, nação e nacionalismo. In: SOBRAL, José Manoel e VALA, Jorge (Org.). Identidades nacionais: inclusão e exclusão. Lisboa: ICS, 2010. 
Cidade Ferreira Viana - Organização da Guarda Civil. Abril/1931. Centro de Memória Ferreira Vianna (documento datilografado, 1 página).

DARNTON, Robert. O grande massacre dos gatos, e outros episódios da história cultural francesa. 5. ed. Local: Ed. Graal, 1986.

FARIA FILHO, Luciano Mendes de; BERTUCCI, Liane Maria. Experiência e cultura: contribuições de E. P. Thompson para uma história social da escolarização. Currículo sem Fronteiras, v. 9, n.1, p. 10 - 24, jan/jun. 2009. Disponível em: <wWw.curriculosemfronteiras.org >. Acesso em 01.08.2011.

FOUCAULT, Michel. Ditos \& escritos II. Tradução de Elisa Monteiro. Rio de Janeiro: Forense, 2000.

FOUCAULT, Michel. A arqueologia o saber. 8. ed., Local: Ed. Forense Universitária, 2012.

FRAGA, André Barbosa. Os heróis da pátria: política cultural e história do Brasil no governo Vargas, 2012. 157 f. Dissertação (Mestrado em História) - Universidade Federal Fluminense, Niterói. 2012.

GINZBURG, Carlo. Mitos, emblemas, sinais: morfologia e história. São Paulo: Companhia das Letras, 1989.

GONÇALVES, Nádia Gaiofatto. O arquivo histórico escolar, a universidade e a escola: diálogos possíveis. Cadernos de Educação, Pelotas: FaE/PPGE/UFPel, v.00, n.00, p. 71 84, jul/dez, 2008.

HALBWACHS, Maurice. A memória coletiva. São Paulo: Centauro, 2003.

HANSEN, Patrícia Santos. Brasil, um país novo: literatura cívico-pedagógica e a construção de um ideal de infância brasileira na Primeira República. 2007, 330 f. Tese (Doutorado em História) - Universidade de São Paulo, Programa de Pós-graduação em História, São Paulo, 2007.

HEYMANN, Luciana. Indivíduo, memória e resíduo histórico: uma reflexão sobe arquivos pessoais e o caso Filinto Müller. Revista Estudos Históricos, v. 00, n. 00, p.41 - 66, 1997.

JULIA, Dominique. A cultura escolar como objeto histórico. Revista Brasileira de História da Educação. n. 1, jan/jun. 2001. Disponível em:

<http://www.rbhe.sbhe.org.br/index.php/rbhe/article/view/273>. Acesso em 01.05.2011.

Livro de Nomeações de funcionários, docentes e administrativos - 1921 - 1938 (Colégio Pedro II - Internato). Arquivo do Colégio Pedro II.

Livro de Partes Diárias das Inspetoras. Centro de Memória Ferreira Vianna. 02.12.1931 28.09.1933.

MEDEIROS, Ruy Hermann Araújo. Arquivos escolares - breve introdução a seu conhecimento. Anais do Colóquio do museu pedagógico, Vitória da Conquista: Universidade Estadual do Sudoeste da Bahia, n. 3, 2003. 
MOGARRO, Maria João. Arquivos e educação: a construção da memória educativa. Revista Brasileira de História da Educação, Local: SBHE, n. 00, v. 00, p.75-99, jul/dez. 2005 .

NORA, Pierre. Entre memória e história: a problemática dos lugares. Projeto História Revista do Programa de Estudos Pós-graduados em História e do Departamento de História. v. 10, p. 00-00, 1993.

Ofício n² 262, de 13 de julho de 1931, da Diretoria Geral de Instrução Pública para o Diretor do Instituto Ferreira Vianna.

Ofício $n^{\circ} 146$, de 21 de julho de 1931, do Diretor do Instituto Ferreira Vianna para o Dr. Diretor Geral de Instrução Pública, em resposta ao ofício recebido, de $n^{\circ} 262$, de 13.07.1931.

Ofício $n^{\circ} 24$, de 28 de janeiro de 1931, do diretor do Instituto Ferreira Vianna para o Dr. Subdiretor Técnico da Diretoria Geral de Instrução, com a listagem dos menores matriculados e data de nascimento de cada um, conforme solicitação no edital do jornal oficial.

Ofício Interno do diretor José Piragibe às Inspetoras de disciplina. Abril/1931. Centro de Memória Ferreira Vianna (documento datilografado, 1 página).

OLIVEIRA, Mariza da Gama Leite de. Arquivos escolares: fontes para a história da educação. In: CONGRESSO NACIONAL DE EDUCAÇÃO - EDUCERE, 11, 2013, Curitiba. Anais... Paraná: PUCPR, 2013, pp. 21087 - 21099. Disponível em: <http://educere.bruc.com.br/ANAIS2013/pdf/10233_5809.pdf.>. Acesso em 02 out. 2013.

OLIVEIRA, Mariza da Gama Leite de. Debates e embates na instrução pública primária e seus efeitos nas práticas do Instituto Ferreira Vianna (Rio de Janeiro, 1929 - 1940). Tese (Doutorado em Educação) - Faculdade de Educação, Universidade Federal do Rio de Janeiro (UFRJ), Rio de Janeiro, março de 2015.

Partes do Prefeito. 28.11.1931. Centro de Memória Ferreira Vianna (documento manuscrito, 1 página).

PAULILO, André Luiz et. al. Arquivo Fernando Azevedo: instrumentos e pesquisa em fonte primária. In: FARIA FILHO, Luciano Mendes de (Org.). Pesquisa em história da educação: perspectivas de análise e objetos e fontes. Belo Horizonte: HG Edições, 1999. p. 201-208.

PAULILO, André Luiz. A estratégia como invenção: as políticas públicas de educação na cidade do Rio de Janeiro entre 1922 e 1935. São Paulo, 2007. 430f. Tese (Doutorado em Educação) - Universidade de São Paulo, Faculdade de Educação, 2007. Disponível em: <http://www.usp.br/niephe/publicacoes/docs/Tese_Paulilo.pdf>. Acesso em: 02 out. 2013.

PAULILO, André Luiz. As estratégias de administração das políticas públicas de educação na cidade do Rio de Janeiro entre 1922 e 1935. Revista Brasileira de Educação. v. 14, n. 42. p. 440-455, set/dez 2009. 
PAULILO, André Luiz. Uma historiografia da modernidade educacional. In: Est. Hist., Rio de Janeiro, v. 23, n. 45, p. 27- 49, jan/jun 2010.

PINTO, Diana de Souza; FARIAS, Francisco Ramos de (Orgs). Novos apontamentos em memória social. Rio de Janeiro: 7 Letras, 2012.

POLLAK, Michael. Memória, esquecimento, silêncio. Estudos Históricos. Rio de Janeiro, v. 2, n.3, p. 3-15, 1989.

RÉMOND, René. Uma história presente. In: RÈMOND, René (Org.). Por uma história política. 2. ed. Rio de Janeiro: FGV, 2003. p.13-36.

RIBEIRO, Marcus Venício. Os arquivos das escolas. In: NUNES, Clarice. (Org.). Guia preliminar de fontes para a história da educação brasileira. Rio de Janeiro: INEP, 1992. pp. $47-64$.

RIZZINI, Irma. Assistência à infância no Brasil: uma análise de sua construção. Rio de Janeiro: Editora Universitária Santa Úrsula, 1993.

RIZZINI, Irma. Meninos desvalidos e menores transviados: a trajetória da assistência pública até a Era Vargas. In: RIZZINI, Irene; PILOTTI, Francisco (Orgs.). A arte de governar crianças: a história das políticas sociais, da legislação e da assistência à infância no Brasil. 3. ed. São Paulo: Cortez, 2011, p. 225 - 286.

SERRANO, Jonathas. O professor Piragibe. [s.d.] Recorte de jornal sem identificação, s/d. Arquivo pessoal da família.

SOUZA, Rosa Fátima de. A militarização da infância: expressões do nacionalismo na cultura brasileira. Cadernos Cedes, ano XX, n. 52. p. 00-00, nov. 2000.

SOUZA, Rosa Fátima de. Preservação do patrimônio histórico escolar no Brasil: notas para um debate. Revista Linhas, Florianópolis, v. 14, n. 26, p. 199 - 221, jan/jun. 2013.

THOMPSON, Edward Palmer. Costumes em comum. São Paulo: Companhia das Letras, 1998. 